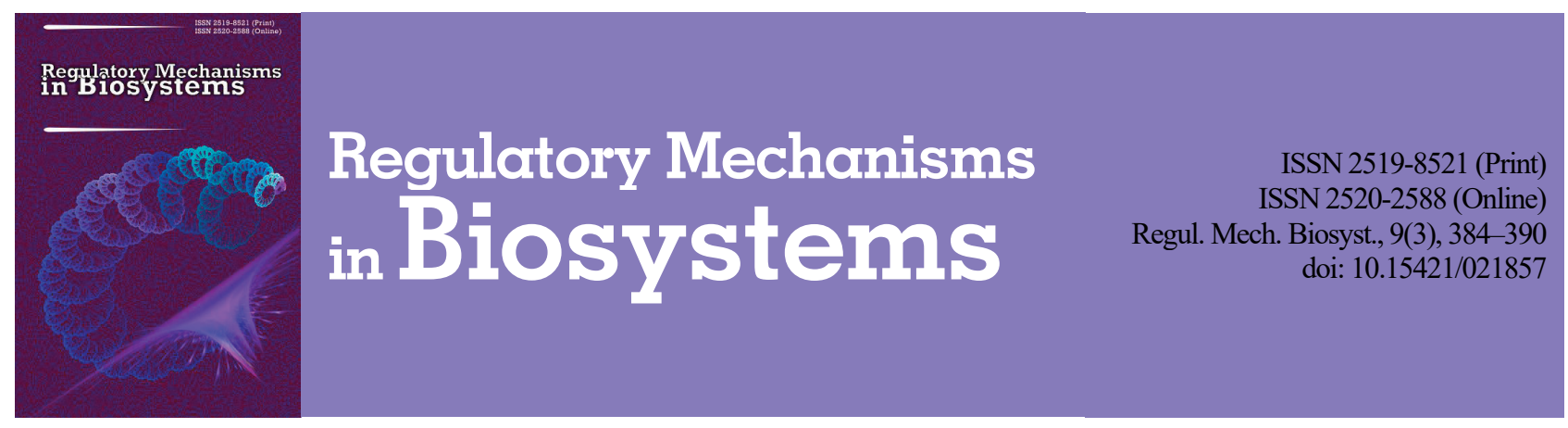

\title{
Biochemical screen correction possibilities in patients with non-alcoholic fatty liver disease with diabetes mellitus
}

\author{
S. V. Feisa, M. V. Rostoka-Reznikova, M. I. Tovt-Korshynska, L. T. Siksai \\ Uzhhorod National University, Uzhhorod, Ukraine
}

Article info

Received 10.07.2018

Received in revised form

17.08 .2018

Accepted 19.08.2018

Uzhhorod National

University,

Sobranetska st., 148,

Uzhhorod, 88000, Ukraine.

Tel.: +38-050-560-08-47.

E-mail:

snizhana.feysa@uzhnu.edu.ua

Feisa, S. V., Rostoka-Reznikova, M. V., Tovt-Korshynska, M. I., \& Siksai, L. T. (2018). Biochemical screen correction possibilities in patients with non-alcoholic fatty liver disease with diabetes mellitus. Regulatory Mechanisms in Biosystems, 9(3), 384-390. doi:10.15421/021857

The rationale for this study is the controversial data regarding the efficacy of hepatoprotectors and antioxidants for lipid profile correction in non-alcoholic fatty liver disease, the prevalence of which is increasing especially in association with diabetes mellitus. We examined 100 non-alcoholic fatty liver disease patients (40-75 years old) with concomitant type 2 diabetes mellitus ( $\mathrm{n}=73$ ) or without it $(n=27)$, the groups were standardized by age and gender. In patients with non-alcoholic fatty liver disease with diabetes mellitus we revealed significantly higher rates of total cholesterol, triglycerides and atherogenic factor in association with a significantly lower high-density lipoproteins level versus the group of patients without concomitant diabetes. We recommended the modification of lifestyle as basic management of their condition to all patients, hypoglycemic therapy with metformin to persons with concomitant diabetes mellitus and rosuvastatin to patients with non-alcoholic fatty liver disease without diabetes. In addition, 25 patients received essential phospholipids ( 2 caps. 3 times a day) and omega-3 polyunsaturated fatty acids (1000 mg per day) for 3 months; 26 patients $-\alpha$-lipoic acid (600 mg daily) for 3 months, 22 patients received rosuvastatin (10 mg daily), 27 patients with non-alcoholic fatty liver disease without diabetes mellitus received rosuvastatin (10 $\mathrm{mg}$ daily). We evaluated the treatment efficiency after 3 months treatment, and the remote consequences - 12 months after the start of combined treatment. After 3 months, the alanine-aminotransferase rate had decreased by $15.1 \%$ in the group taking combined essential phospholipids and $\omega 3$-polyunsaturated fatty acids and by $12.9 \%$ in the group taking alpha-lipoic acid, which was significantly larger than in the rosuvastatin group (7.5\%); gamma-glutamate transpeptidase level decreased by $16.7 \%, 18.7 \%$ and $9.4 \%$ respectively indicating anticholestatic and hepatoprotective effect of both proposed treatment combinations. The same tendency of cytolysis and cholestasis processes inhibition was observed after 12 months as well. In conclusion, the combination of standard treatment with antioxidant and hepatoprotective agents (omega-3 polyunsaturated fatty acids with essential phospholipids or only alpha-lipoic acid) promotes both cytolysis and cholestasis syndromes inhibition in non-alcoholic fatty liver disease patients with concomitant type 2 diabetes mellitus.

Keywords: type 2 diabetes mellitus; dyslipidemia; hepatoprotectors; essential phospholipids; omega-3 polyunsaturated fatty acids; alpha-lipoic acid.

\section{Introduction}

Non-alcoholic fatty liver disease (NAFLD) is a multi-stage disease that starts with excessive (over 5\%) lipids (predominantly triglycerides) accumulation in hepatocytes (hepatosteatosis stage) (Brunt \& Tiniakos, 2010; Takahashi \& Fukusato, 2014), progresses to the development of necrotic inflammation liver parenchyma (steatohepatitis stage) (Schleicher et al., 2014) and associated with risk factors (obesity, type 2 diabetes mellitus (DM-2), dyslipidemia, genetic predisposition) (Jonathan et al., 2016; Stepanov et al., 2018). NAFLD is the most common liver disease with $6.3-33.0 \%$ prevalence in the general population (Loomba \& Sanyal, 2013; Lombardi et al., 2017; Perazzo \& Dufour, 2017). NAFLD can be diagnosed in every third inhabitant of the planet (Anavi et al., 2017; Williams et al., 2011; Lazo et al., 2013). The frequency of its detection in adults depends on diagnosis method (Lee, 2017), age, gender, ethnicity (Dajani et al., 2015; Berzigotti et al., 2018) and presence of comorbidity (Dajani \& Abu Hammour, 2016). NAFLD can progress to non-alcoholic steatohepatitis (NASH) in about 30\% of cases (Michelotti et al., 2013; Firneisz, 2014; Sharma et al., 2015; Lee et al., 2017).

The high risk groups of NAFLD include people with abdominal obesity, DM-2, hypercholesterolemia, metabolic syndrome (Sumida et al., 2014; Stepanov et al., 2018). According to Gastaldelli (2007), NAFLD is diagnosed in $57 \%$ of obesity patients and $72 \%$ of DM- 2 patients. Almost $90 \%$ of patients with severe obesity demonstrate the signs of NAFLD (Machado \& Cortez-Pinto, 2014). Prevalence of NAFLD in dyslipidemia patients is estimated at $50 \%$ and characterized by increased triglycerides (TG) rate and decreased low density lipoproteins (LDL) level (Nseir \& Mahamid, 2013). In the case of DM-2, NAFLD more often progresses to NASH. Prevalence of NASH in DM-2 patients is $12.2 \%$ versus $7.4 \%$ in patients without diabetes and in cases of coexistent DM-2 and obesity the rate of NASH reaches $21-40 \%$ (Ballestri, 2016).

Considering the close link of NAFLD and obesity, dyslipidemia, arterial hypertension and metabolic syndrome (MS) and their common pathogenesis based on insulin resistance (IR), NAFLD is reasonably named as hepatic manifestation of MS (Ballestri, 2016). IR can lead to NAFLD and NAFLD can cause hepatic IR, so NAFLD patients are at high risk of complete MS or its development of its components especially DM-2 (Gaggini et al., 2013; Firneisz, 2014). In addition to higher probability of death due to hepatic complications (liver failure, portal hypertension complications, hepatocellular carcinoma) (Armstrong et al., 2014), those patients are prone to higher incidence of cardiovascular diseases (Patel et al., 2017). The dangerous feature of NAFLD is an asymptomatic course especially during the initial stage (hepatosteatosis) which can be presented without lab tests showing abnormalities, which makes it 
difficult and sometimes even impossible to diagnose in time and start the early treatment for prevention of both hepatic and extrahepatic complications. Often the only changes in the laboratory picture of NAFLD patients are the initial signs of prediabetes or DM-2 ( often diagnosed for the first time ) - diseases that create a background predisposition to liver steatosis development.

The first aspect of effective NAFLD treatment is a life style modification: low calorie diet, increase in physical activity, cessation of smoking (Verbeek et al., 2013; Kim, 2017; Newsome et al., 2018). The gradual reduction in body weight is particularly important when NAFLD is a component of MS (Federico et al., 2017; Babio, 2014). Pharmacological treatment in NAFLD patients is to be considered in case of NASH or in case of comorbidity - steatohepatosis with cardiometabolic disorders (obesity, dyslipidemia, arterial hypertension, DM-2) (Lombardi et al., 2017). According to the recommendations of the European Association for the Study of the Liver (EASL), the European Association for the Study of Diabetes (EASD) and the European Association for the Study of Obesity (EASO) (2016), a pharmacological treatment can be prescribed not only to patients with liver fibrosis of $\mathrm{F}_{2}$ stage but in case of high probability of the disease progression (concomitant DM-2, MS, recurrent high ALT level detection, high intensity of inflammation) and includes pioglitazone, Vitamin E or their combination, statins, omega-3 polyunsaturated fatty acids (EASL-EASD-EASO, 2016).

Considering that NAFLD is characterized by comorbidity which often leads to polypharmacy (Patel et al., 2017), the medicines with multiple effects that influence different ethio-pathogenic links of clinical and laboratory presentation of NFLD should be preferred in those patients (Berlanga et al., 2014).

Although the current recommendations (EASL-EASD-EASO, 2016; Ganesh \& Rustgi, 2016) don't include indications regarding prescription of hepatoprotectors (Dajani \& Abu Hammour, 2016) there are publications about their advisability as well as medicines with cytoprotective (Gonciarz et al., 1988; Gundermann et al., 2016) and antioxidant (de Oliveira et al., 2011; Basu et al., 2014) effects that constitute a pathogenetically reasonable approach in case of NAFLD. It has been proven that the function of hepatocytes correction leads to enhanced treatment effect due to indirect impact on IR degree (Dajani \& Abu Hammour, 2016).

Considering their combined effects, cytoprotective, anti-inflammatory, hypotrigliceridemic and antioxidant effects, essential phospholipids (EPL), omega-3 polyunsaturated fatty acids (PUFA) and alpha-lipoic (thioctic) acid (ALA) attracted our attention. The main component of EPL is a phosphocholine which contains PUFA (Dajani et al., 2015; Padma et al., 2013). Building up in the hepatocyte membranes, EPL improve membrane-dependent function, showing anti-inflammatory, antifibrotic, apoptosis-modulating, regenerative effects (Gundermann et al., 2016). ALA works as a coenzyme in the ketoacids oxidative decarboxylation, takes part in the cell energy metabolism and shows antitoxic and antioxidant effects (Kajikawa et al., 2011; Stankovic et al., 2014). In DM-2 patients ALA decreases IR, inhibits peripheral neuropathy development and glycogen accumulation in the liver, influences cholesterol metabolism, helps to reduce blood glucose level, takes part in lipid and carbohydrates metabolism regulation, improves liver function due to its hepatoprotector, antioxidant, detoxication effect. Use of omega-3 PUFA in NAFLD with DM-2 patients is advisable and reasonable for hyperlipidemia correction (Di Minno et al., 2012) since their hypotrigliceridemic effect allows this group to be considered as a possible alternative to statins. The high prevalence on NAFLD and DM-2 and the lack of consensus regarding the use of EPL, ALA and omega-3 PUFA in such patients determine the relevance of this work and justify the necessity of conducting a clinical study of their effect on patients with NAFLD and DM-2. The objective of this article is to investigate biochemical screen of liver function, lipid and carbohydrate metabolism in NAFLD patients and evaluate the effect of combined treatment with omega-3 PUFA, EPL and ALA use.

\section{Materials and methods}

We examined 73 patients with NAFLD and DM-2 who were treated at the Therapy and Family Medicine Department of Uzhhorod
National University in 2011-2017. The patients were 40-71 years old $(50.5 \pm 5.8$ years on average). $49(67.1 \%)$ of patients were males and 24 (32.9\%) - women. 30 healthy adults (20 men, 10 women with an average age of $49.5 \pm 5.5$ years) were examined as the control group. The groups were standardized by the age and gender.

The NAFLD diagnosis was considered according to the EASLEASD-EASO Clinical Practice Guidelines for the Management of NonAlcoholic Fatty Liver Disease (2016). Inclusion criteria were confirmed diagnoses of NAFLD and DM-2. Exclusion criteria were viral, autoimmune, alcohol and toxic (drug-induced, iatrogenic) liver disease, cardiovascular diseases decompensation, collagenosis (rheumatic diseases), an active or decompensated stage of any other concomitant diseases, infectious diseases (including tuberculosis), pregnancy, breast feeding and psychiatric diseases that violated the patient's ability to evaluate his / her condition and discuss the disease's management. Patients that refused to sign an informed consent for participation in the study were also excluded from the investigation.

All patients underwent the laboratory tests complex that included total, direct, indirect bilirubin level, uric acid, total protein, albumin, creatinine rates; enzymes activity (alanine-aminotransferase (ALT), aspartate-aminotransferase (AST), gamma-glutamate transpeptidase (GGT), alkaline phosphatase (ALP). The lipid profile investigation included blood levels of total cholesterol (TC), triglycerides (TG); high density lipoproteins (HDL), low density lipoproteins (LDL) and very low density lipoproteins (VLDL) cholesterol; atherogenic index of plasma (AIP) calculation. The lipid metabolism was evaluated by fasting and postprandial blood glucose levels (oral glucose tolerance test - OGTT), glycated hemoglobin (HbA1C). IR was evaluated by HOMA index according to the formula IR-HOMA = (fasting blood glucose $\mathrm{X}$ fasting blood insulin) / 22.5, where X - multiplication and / - division.

The LAP (Lipid Accumulation Product) index was calculated in all patients as the non-invasive liver steatosis index (Bedogni et al., 2010; Dai et al., 2017) according to the formula: $\mathrm{LAP}=(\mathrm{WC}-65) \mathrm{X} \mathrm{TG}$ (for men) or LAP $=(\mathrm{WC}-58) \mathrm{X}$ TG (for women), where: $\mathrm{WC}-$ waist circumference in $\mathrm{cm}, \mathrm{X}$ - multiplication, $\mathrm{TG}$ - blood triglycerides level in $\mathrm{mmol} / \mathrm{l}$. LAP over 4.28 was interpreted as liver steatosis.

The average ranges of the groups of all laboratory tests were calculated in NAFLD with DM-2 patients before the start of treatment and compared to those of the control group for evaluation of NAFLD and DM-2 laboratory characteristics.

Management of all patients included life style modification with moderate exertion (walking for at least $30 \mathrm{~min}$ every day) and diet correction ( 5 food intakes daily: 3 large meals and 2 small ones; limited fast-digesting carbohydrates and animal fats consumption, adequate water intake, $15 \%$ deficit in daily caloric intake). All patients received hypoglycemic therapy with metformin, which is proven to reduce IR.

The study design required 3 groups of NAFLD patients in accordance to the proposed combined treatment. Group 1 included 25 patients who received EPL (medicine Essentiale Forte H) 2 capsules TID and omega-3 PUFA $1000 \mathrm{mg}$ daily, group 2-26 patients who received ALA (per os) $600 \mathrm{mg}$ daily. Group 3 included patients who didn't receive any medicine with hepatoprotective and antioxidant effect; they received rosuvastatin ( $10 \mathrm{mg}$ daily) for dyslipidemia correction.

The effect of different combinations was evaluated after 3 months of treatment by comparison of average group laboratory test ranges with respective baseline tests. The remote consequences were estimated 12 months after the start of combined treatment by comparison of the laboratory tests to baseline, 3 month and control group results.

The statistical analysis included Microsoft Excel table base of patients and Statistica 10.0 (StatSoft Inc., USA) software use. Treatment group differences were evaluated using the independent sample t-test in case of normal distribution and the Mann-Whitney test for non-parametric data. The significance of changes in evaluated indices after treatment in normal distribution was evaluated using the Student two-tailed test and in case of non-normal distribution - the Wilcoxon test respecttively. The difference was considered as significant at $\mathrm{P}<0.05$. All quantitative indices were presented in $(x \pm S D)$ design, where $x$ is a mean group value and $\mathrm{SD}-$ its standard deviation. 


\section{Results}

Biochemical screen of NAFLD patients with concomitant DM-2 is shown in Table 1, where mean group values are presented in comparison to control group values and the group of patients with NAFLD without diabetes. The mentioned indices were evaluated before treatment and characterize baseline values of NAFLD patients.

Table 1

Biochemical screen of NAFLD patients with concomitant type 2 diabetes mellitus versus NAFLD patients without diabetes and control group $(\mathrm{x} \pm \mathrm{SD})$

\begin{tabular}{lccc}
\hline \multicolumn{1}{c}{ Index } & $\begin{array}{c}\text { NAFLD with } \\
\text { DM-2 }(\mathrm{n}=73)\end{array}$ & $\begin{array}{c}\text { NAFLD without } \\
\mathrm{DM}(\mathrm{n}=27)\end{array}$ & $\begin{array}{c}\text { Control group } \\
(\mathrm{n}=30)\end{array}$ \\
\hline Fasting blood glucose, $\mathrm{mmol} / \mathrm{l}$ & $11.1 \pm 1.78^{* \#}$ & $6.23 \pm 0.66$ & $4.08 \pm 0.59$ \\
HbA1C, \% & $7.87 \pm 0.52^{*} \#$ & $6.04 \pm 0.24$ & $5.13 \pm 0.44$ \\
IR-HOMA, units & $9.34 \pm 3.42^{\#}$ & $6.32 \pm 3.35$ & $2.33 \pm 0.23$ \\
Total cholesterol, mmol/1 & $5.84 \pm 0.68^{\#}$ & $5.18 \pm 0.56$ & $4.03 \pm 0.66$ \\
Triglycerides, mmol/l & $2.77 \pm 0.60^{\#}$ & $2.51 \pm 0.41$ & $1.84 \pm 0.26$ \\
HDL, mmol/l & $0.91 \pm 0.10^{*}$ & $1.16 \pm 0.11$ & $2.27 \pm 0.76$ \\
LDL, mmol/l & $3.67 \pm 0.47$ & $2.87 \pm 0.41$ & $2.71 \pm 0.34$ \\
VLDL, mmol/l & $1.26 \pm 0.27$ & $1.15 \pm 0.19$ & $0.83 \pm 0.13$ \\
IAP, units & $5.48 \pm 0.68^{\#}$ & $3.50 \pm 0.64$ & $2.15 \pm 0.43$ \\
ALT, IU/l & $37.90 \pm 10.52^{\#}$ & $27.40 \pm 8.61$ & $12.56 \pm 3.12$ \\
AST, IU/l & $33.80 \pm 11.98^{\#}$ & $22.06 \pm 5.26$ & $8.32 \pm 2.89$ \\
GGT, IU/l & $39.30 \pm 12.55^{\#}$ & $21.30 \pm 12.68$ & $10.24 \pm 3.61$ \\
ALP, IU/l & $94.81 \pm 14.05^{*} \#$ & $38.41 \pm 15.73$ & $46.57 \pm 7.13$ \\
Total protein, g/l & $70.60 \pm 3.03$ & $70.11 \pm 5.57$ & $73.86 \pm 2.56$ \\
Bilirubin total, mcmol/l & $9.74 \pm 1.82$ & $13.03 \pm 4.08$ & $10.01 \pm 1.24$ \\
Bilirubin direct, mcmol/l & $3.42 \pm 0.90$ & $3.70 \pm 0.61$ & $3.40 \pm 0.76$ \\
Creatinine, mcmol/l & $77.25 \pm 11.51$ & $78.42 \pm 25.50$ & $78.91 \pm 8.22$ \\
Uric acid, mcmol/l & $336.2 \pm 53.97$ & $269.3 \pm 90.02$ & $280.21 \pm 22.30$ \\
\hline
\end{tabular}

Notes: * - significant difference in NAFLD and DM-2 versus NAFLD without DM-2 patients, $\mathrm{P}<0.05 ;{ }^{\#}$ - significant difference in NAFLD patients versus control group, $\mathrm{P}<0.05$.

We observed positive dynamics of carbohydrate metabolism indices after treatment (Table 2). The fasting blood glucose and HbA1C rates decreased the most significantly in Group 2 showing additional hypoglycemic effect of ALA. In Group 1 the changes of the mentioned indices after treatment were also significantly different but less pronounced. In Group 3 the rates of those indices decreased as well but without significant difference $(\mathrm{P}>0.05)$. The IR-HOMA rate was reduced in all groups but significance of those changes was confirmed only in Group 2 after 12 months apart from the treatment start.

Table 2

The treatment influence on carbohydrate metabolism indices in NAFLD patients with DM-2 $(x \pm \mathrm{SD})$

\begin{tabular}{|c|c|c|c|c|}
\hline & Index & $\begin{array}{c}\text { Group } 1 \text { (essential } \\
\text { phospholipids: } 2 \text { capsu- } \\
\text { les } 3 \text { times a day }+ \\
\text { omega-3 polyunsatura- } \\
\text { ted fatty acids, } 1000 \mathrm{mg} \\
\text { daily; } \mathrm{n}=25 \text { ) }\end{array}$ & $\begin{array}{c}\text { Group } 2 \\
\text { (alfa lipoic } \\
\text { acid, } 600 \mathrm{mg} \\
\text { daily per os; } \\
\mathrm{n}=26 \text { ) }\end{array}$ & $\begin{array}{c}\text { Group } 3 \\
\text { (rosuvastatin, } \\
10 \text { mg daily; } \\
\mathrm{n}=22 \text { ) }\end{array}$ \\
\hline \multirow{3}{*}{$\begin{array}{l}\text { Fasting } \\
\text { blood } \\
\text { glucose, } \\
\mathrm{mmol} / \mathrm{l}\end{array}$} & \multirow{3}{*}{$\begin{array}{l}\text { before treatment } \\
\text { after } 3 \text { months } \\
\text { treatment } \\
12 \text { months after the } \\
\text { start of treatment }\end{array}$} & $10.82 \pm 1.91$ & $11.27 \pm 2.13$ & $11.21 \pm 1.02$ \\
\hline & & $10.08 \pm 0.30^{*}$ & $9.60 \pm 0.26^{*}$ & $10.10 \pm 0.62$ \\
\hline & & $9.13 \pm 1.16^{*}$ & $8.52 \pm 0.97^{*}$ & $9.40 \pm 0.62 *$ \\
\hline \multirow{3}{*}{$\begin{array}{l}\mathrm{HbA} 1 \mathrm{C}, \\
\%\end{array}$} & \multirow{2}{*}{$\begin{array}{l}\text { before treatment } \\
\text { after } 3 \text { months } \\
\text { treatment }\end{array}$} & $7.88 \pm 0.49$ & $7.77 \pm 0.57$ & $7.99 \pm 0.52$ \\
\hline & & $7.67 \pm 0.09$ & $7.47 \pm 0.08$ & $7.77 \pm 0.91$ \\
\hline & $\begin{array}{l}12 \text { months after the } \\
\text { start of treatment }\end{array}$ & $7.46 \pm 0.36^{*}$ & $7.26 \pm 0.36^{*}$ & $7.56 \pm 0.36$ \\
\hline \multirow{3}{*}{$\begin{array}{l}\text { IR- } \\
\text { HOMA } \\
\text { (units) }\end{array}$} & \multirow{3}{*}{$\begin{array}{l}\text { before treatment } \\
\text { after } 3 \text { months } \\
\text { treatment } \\
12 \text { months after the } \\
\text { start of treatment }\end{array}$} & $8.18 \pm 2.04$ & $9.72 \pm 3.74$ & $13.17 \pm 5.15$ \\
\hline & & $7.60 \pm 1.81$ & $8.57 \pm 3.53$ & $12.10 \pm 4.74$ \\
\hline & & $7.82 \pm 2.30 *$ & $8.71 \pm 3.20^{*}$ & $10.65 \pm 2.17$ \\
\hline
\end{tabular}

Notes: * - significant changes after treatment versus before treatment, $\mathrm{P}<0.05$.

The lipid profile of NAFLD before treatment was characterized by hypercholesterolemia and dyslipidemia, which were presented with hy- pertriglyceridemia, high LDL, VLDL and significantly decreased HDL levels. It led to significantly higher AIP in NAFLD with DM-2 patients $(5.48 \pm 0.68)$ versus NAFLD without $\mathrm{DM}-2$ patients $(3.50 \pm 0.64, \mathrm{P}<0.05)$. This index was 2.55 fold higher in NAFLD with DM-2 patients versus the control group $(2.15 \pm 0.43)$. The changes in lipid profile after treatment, shown in Table 3, demonstrate the good effect of the treatment of all combinations.

Table 3

The changes in lipid profile of NAFLD with DM-2 patients after treatment $(\mathrm{x} \pm \mathrm{SD})$

\begin{tabular}{|c|c|c|c|c|}
\hline & Index & $\begin{array}{l}\text { Group } 1 \text { (essential } \\
\text { phospholipids: } \\
2 \text { capsules } 3 \text { times a } \\
\text { day + omega-3 poly- } \\
\text { unsaturated fatty acids, } \\
1000 \text { mg daily; } n=25 \text { ) }\end{array}$ & $\begin{array}{c}\text { Group } 2 \\
\text { (alfa lipoic } \\
\text { acid, } 600 \mathrm{mg} \\
\text { daily per os; } \\
\mathrm{n}=26 \text { ) }\end{array}$ & $\begin{array}{c}\text { Group } 3 \\
\text { (rosuvastatin, } \\
10 \text { mg daily; } \\
\mathrm{n}=22 \text { ) }\end{array}$ \\
\hline \multirow{3}{*}{$\begin{array}{l}\text { Total } \\
\text { choles- } \\
\text { terol, } \\
\mathrm{mmol} / \mathrm{l}\end{array}$} & \multirow{3}{*}{$\begin{array}{l}\text { before treatment } \\
\text { after } 3 \text { months } \\
\text { treatment } \\
12 \text { months after the } \\
\text { start of treatment }\end{array}$} & $5.80 \pm 0.65$ & $5.84 \pm 0.54$ & $5.87 \pm 0.87$ \\
\hline & & $5.45 \pm 0.10^{*}$ & $5.28 \pm 0.07 *$ & $5.17 \pm 0.59$ \\
\hline & & $5.22 \pm 0.31 *$ & $5.05 \pm 0.44^{*}$ & $4.90 \pm 0.44^{*}$ \\
\hline \multirow{3}{*}{$\begin{array}{l}\text { Triglyce } \\
\text { rides, } \\
\mathrm{mmol} / \mathrm{l}\end{array}$} & \multirow{3}{*}{$\begin{array}{l}\text { before treatment } \\
\text { after } 3 \text { months } \\
\text { treatment } \\
12 \text { months after the } \\
\text { start of treatment }\end{array}$} & $2.86 \pm 0.51$ & $2.60 \pm 0.53$ & $2.86 \pm 0.74$ \\
\hline & & $2.45 \pm 0.08$ & $2.17 \pm 0.08$ & $2.28 \pm 0.56$ \\
\hline & & $1.94 \pm 0.16^{*}$ & $1.98 \pm 0.41^{*}$ & $1.97 \pm 0.34$ \\
\hline \multirow{3}{*}{$\begin{array}{l}\mathrm{HDL}, \\
\mathrm{mmol} / \mathrm{l}\end{array}$} & \multirow{3}{*}{$\begin{array}{l}\text { before treatment } \\
\text { after } 3 \text { months } \\
\text { treatment } \\
12 \text { months after the } \\
\text { start of treatment }\end{array}$} & $0.90 \pm 0.11$ & $0.90 \pm 0.08$ & $0.92 \pm 0.13$ \\
\hline & & $0.98 \pm 0.15$ & $0.98 \pm 0.01$ & $0.99 \pm 0.09$ \\
\hline & & $1.11 \pm 0.09 *$ & $1.07 \pm 0.70^{*}$ & $1.05 \pm 0.07$ \\
\hline \multirow{3}{*}{$\begin{array}{l}\mathrm{LDL} \text {, } \\
\mathrm{mmol} / \mathrm{l}\end{array}$} & \multirow{3}{*}{$\begin{array}{l}\text { before treatment } \\
\text { after } 3 \text { months } \\
\text { treatment } \\
12 \text { months after the } \\
\text { start of treatment }\end{array}$} & $3.59 \pm 0.46$ & $3.76 \pm 0.33$ & $3.65 \pm 0.62$ \\
\hline & & $3.36 \pm 0.07 *$ & $3.31 \pm 0.04^{*}$ & $3.13 \pm 0.42 *$ \\
\hline & & $3.23 \pm 0.26^{*}$ & $3.08 \pm 0.31 *$ & $2.95 \pm 0.35^{*}$ \\
\hline \multirow{3}{*}{$\begin{array}{l}\text { VLDL, } \\
\mathrm{mmol} / 1\end{array}$} & \multirow{3}{*}{$\begin{array}{l}\text { before treatment } \\
\text { after } 3 \text { months } \\
\text { treatment } \\
12 \text { months after the } \\
\text { start of treatment }\end{array}$} & $1.31 \pm 0.23$ & $1.18 \pm 0.24$ & $1.30 \pm 0.34$ \\
\hline & & $1.12 \pm 0.04 *$ & $0.99 \pm 0.04 *$ & $1.04 \pm 0.26^{*}$ \\
\hline & & $0.88 \pm 0.07 *$ & $0.90 \pm 0.18^{*}$ & $0.89 \pm 0.15^{*}$ \\
\hline \multirow{3}{*}{$\begin{array}{l}\text { IAP, } \\
\text { units }\end{array}$} & \multirow{3}{*}{$\begin{array}{l}\text { before treatment } \\
\text { after } 3 \text { months } \\
\text { treatment } \\
12 \text { months after the } \\
\text { start of treatment }\end{array}$} & $5.45 \pm 0.74$ & $5.53 \pm 0.56$ & $5.44 \pm 0.75$ \\
\hline & & $4.56 \pm 0.10^{*}$ & $4.40 \pm 0.07 *$ & $4.20 \pm 0.41^{*}$ \\
\hline & & $3.74 \pm 0.44^{*}$ & $3.74 \pm 0.52 *$ & $3.70 \pm 0.49 *$ \\
\hline
\end{tabular}

Notes: * - significant changes after treatment versus before treatment, $\mathrm{P}<0.05$.

In cases of NAFLD, free fats, mostly triglycerides, are accumulated in hepatocytes, which is characterized by the common ultrasound conclusion of a "fatty liver". Excessive accumulation of fats in the liver can be detected by the non-invasive method of the lipid products accumulation (LAP) index (Bedogni et al., 2010). One of the indicators of the effect of treatment is a reduction in liver fats deposits, which is represented not only by positive biochemical screen and liver ultrasound dynamics but also the LAP index reduction. Table 4 demonstrates the changes in the LAP index after treatment: in Group 1 the LAP index had decreased 1.59 times after 3 months treatment as well as in Group 2, while in Group 3 these changes were less significant and LAP index decreased only 1.44 times. The remote consequences that were evaluated 12 months after the start of treatment showed the LAP index reduction versus mean group values before treatment of 3.13 fold in Group 1; 2.67 fold in Group 2 and only 1.98 fold - in Group 3.

The liver function tests were evaluated in all NAFLD with DM-2 patients. The cytolysis, liver parenchyma inflammation and cholestasis syndromes were revealed. We investigated the influence of different treatment combination on the following liver functions: protein synthesis, pigment and purine metabolism as well as kidney function - the mean values of selected biochemical screen indices in patients with NAFLD and DM-2 after treatment, which are shown in Table 5. The hepatocytes cytolysis intensity was evaluated according to ALT and AST activity indices. 
Table 4

The non-invasive LAP (Lipid Accumulation Products) index changes in NAFLD with DM-2 patients after treatment $(\mathrm{x} \pm \mathrm{SD})$

\begin{tabular}{|c|c|c|c|c|}
\hline & Index & $\begin{array}{l}\text { Group } 1 \text { (essential } \\
\text { phospholipids: } 2 \text { cap- } \\
\text { sules } 3 \text { times a day }+ \\
\text { omega-3 polyunsatu- } \\
\text { rated fatty acids, } \\
1000 \text { mg daily; } \mathrm{n}=25 \text { ) }\end{array}$ & $\begin{array}{c}\text { Group } 2 \\
\text { (alfa lipoic } \\
\text { acid, } 600 \mathrm{mg} \\
\text { daily per os; } \\
\mathrm{n}=26 \text { ) }\end{array}$ & $\begin{array}{c}\text { Group } 3 \\
\text { (rosuvastatin, } \\
10 \text { mg daily; } \\
n=22 \text { ) }\end{array}$ \\
\hline \multirow{3}{*}{$\begin{array}{l}\text { LAP (Lipid } \\
\text { accumula- } \\
\text { tion pro- } \\
\text { ducts) } \\
\text { index, units }\end{array}$} & \multirow{3}{*}{$\begin{array}{l}\text { before treatment } \\
\text { after } 3 \text { months } \\
\text { treatment } \\
12 \text { months after the } \\
\text { start of treatment }\end{array}$} & $164.2 \pm 30.4$ & $144.1 \pm 33.1$ & $157.1 \pm 39.5$ \\
\hline & & $103.5 \pm 14.3$ & $90.8 \pm 13.6^{*}$ & $108.9 \pm 11.9$ \\
\hline & & $52.5 \pm 12.3^{*}$ & $54.0 \pm 22.3^{*}$ & $79.2 \pm 23.9 *$ \\
\hline
\end{tabular}

Notes: * - significant changes after treatment versus before treatment, $\mathrm{P}<0.05$.

Table 5

Changes in selected biochemical screen indices in NAFLD and DM-2 patients after different treatment combinations, $\mathrm{M} \pm \mathrm{m}$

\begin{tabular}{|c|c|c|c|c|}
\hline & Index & $\begin{array}{l}\text { Group } 1 \text { (essential } \\
\text { phospholipids: } 2 \text { cap- } \\
\text { sules } 3 \text { times a day }+ \\
\text { omega-3 polyunsatu- } \\
\text { rated fatty acids, } \\
1000 \text { mg daily; } n=25 \text { ) }\end{array}$ & 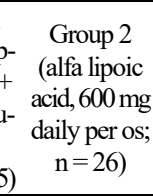 & $\begin{array}{c}\text { Group } 3 \\
\text { (rosuvastatin, } \\
10 \text { mg daily; } \\
n=22 \text { ) }\end{array}$ \\
\hline \multirow{3}{*}{$\begin{array}{l}\text { ALT, } \\
\text { IU/1 }\end{array}$} & before treatment & $37.5 \pm 11.9$ & $36.6 \pm 10.8$ & $39.9 \pm 8.6$ \\
\hline & $\begin{array}{l}\text { after } 3 \text { months } \\
\text { treatment }\end{array}$ & $31.8 \pm 2.0$ & $31.9 \pm 1.8$ & $36.9 \pm 1.8$ \\
\hline & $\begin{array}{l}12 \text { months after the } \\
\text { start of treatment }\end{array}$ & $30.7 \pm 17.0$ & $28.5 \pm 2.2^{*}$ & $34.5 \pm 7.0^{*}$ \\
\hline \multirow{3}{*}{$\begin{array}{l}\text { AST, } \\
\text { IU/1 }\end{array}$} & before treatment & $32.0 \pm 12.7$ & $33.1 \pm 12.1$ & $36.7 \pm 11.0$ \\
\hline & $\begin{array}{l}\text { after } 3 \text { months } \\
\text { treatment }\end{array}$ & $27.2 \pm 2.2$ & $27.9 \pm 1.9$ & $33.7 \pm 2.0$ \\
\hline & $\begin{array}{l}12 \text { months after the } \\
\text { start of treatment }\end{array}$ & $23.9 \pm 9.0$ & $25.1 \pm 6.6^{*}$ & $31.4 \pm 8.4$ \\
\hline \multirow{3}{*}{$\begin{array}{l}\text { GGT, } \\
\text { IU/1 }\end{array}$} & before treatm & $38.7 \pm 9.4$ & $40.8 \pm 15.8$ & $38.0 \pm 11.7$ \\
\hline & $\begin{array}{l}\text { after } 3 \text { months } \\
\text { treatment }\end{array}$ & $32.2 \pm 1.6^{*}$ & $33.2 \pm 2.5$ & $34.4 \pm 2.1$ \\
\hline & $\begin{array}{l}12 \text { months apart } \\
\text { from the treatment } t\end{array}$ & $28.5 \pm 6.7^{*}$ & $29.2 \pm 8.7^{*}$ & $32.9 \pm 9.0$ \\
\hline \multirow{3}{*}{$\begin{array}{l}\text { ALP, } \\
\text { IU/1 }\end{array}$} & before treatment & $94.1 \pm 16.1$ & $91.4 \pm 15.4$ & $99.7 \pm 7.6$ \\
\hline & $\begin{array}{l}\text { after } 3 \text { months } \\
\text { treatment }\end{array}$ & $75.6 \pm 3.0^{*}$ & $73.2 \pm 2.4^{*}$ & $83.3 \pm 3.1^{*}$ \\
\hline & $\begin{array}{l}12 \text { months after the } \\
\text { start of treatment }\end{array}$ & $66.4 \pm 12.1^{*}$ & $63.4 \pm 9.9^{*}$ & $67.4 \pm 7.4^{*}$ \\
\hline \multirow{3}{*}{$\begin{array}{l}\text { Total } \\
\text { protein, } \\
\text { g/l }\end{array}$} & before treatment & $70.4 \pm 3.6$ & $70.1 \pm 2.6$ & $71.4 \pm 2.7$ \\
\hline & $\begin{array}{l}\text { after } 3 \text { months } \\
\text { treatment }\end{array}$ & $74.4 \pm 0.7^{*}$ & $70.6 \pm 0.7$ & $72.6 \pm 0.6$ \\
\hline & $\begin{array}{l}12 \text { months apart } \\
\text { from the treatment } \\
\text { start }\end{array}$ & $71.3 \pm 13.8$ & $71.8 \pm 5.2$ & $73.0 \pm 3.4$ \\
\hline \multirow{3}{*}{$\begin{array}{l}\text { Bilirubin } \\
\text { total, } \\
\mathrm{mcmol} / \mathrm{l}\end{array}$} & before treatment & $9.28 \pm 1.85$ & $10.02 \pm 2.14$ & $9.93 \pm 1.25$ \\
\hline & $\begin{array}{l}\text { after } 3 \text { months } \\
\text { treatment }\end{array}$ & $9.89 \pm 0.37$ & $14.07 \pm 0.69$ & $13.42 \pm 1.89^{*}$ \\
\hline & $\begin{array}{l}12 \text { months after the } \\
\text { start of treatment }\end{array}$ & $10.80 \pm 2.76^{*}$ & $15.30 \pm 2.84^{*}$ & $13.51 \pm 2.23 *$ \\
\hline \multirow{3}{*}{$\begin{array}{l}\text { Bilirubin } \\
\text { total, } \\
\mathrm{mcmol} / \mathrm{l}\end{array}$} & before treatn & $3.32 \pm 0.55$ & $3.59 \pm 1.36$ & $3.30 \pm 0.41$ \\
\hline & $\begin{array}{l}\text { after } 3 \text { months } \\
\text { treatment }\end{array}$ & $3.79 \pm 0.17^{*}$ & $5.34 \pm 0.39 *$ & $5.14 \pm 0.45^{*}$ \\
\hline & $\begin{array}{l}12 \text { months after the } \\
\text { start of treatment }\end{array}$ & $3.71 \pm 1.00$ & $5.42 \pm 1.39 *$ & $4.82 \pm 1.02 *$ \\
\hline \multirow{3}{*}{$\begin{array}{l}\text { Creati- } \\
\text { nine, } \\
\mathrm{mcmol} / \mathrm{l}\end{array}$} & before treatment & $77.9 \pm 12.3$ & $76.9 \pm 11.3$ & $76.8 \pm 11.3$ \\
\hline & $\begin{array}{l}\text { after } 3 \text { months } \\
\text { treatment }\end{array}$ & $78.3 \pm 2.1$ & $85.9 \pm 1.7^{*}$ & $83.9 \pm 3.5^{*}$ \\
\hline & $\begin{array}{l}12 \text { months after the } \\
\text { start of treatment }\end{array}$ & $80.4 \pm 10.3$ & $89.9 \pm 6.1^{*}$ & $86.3 \pm 7.9^{*}$ \\
\hline \multirow{3}{*}{$\begin{array}{l}\text { Uric } \\
\text { acid, } \\
\mathrm{mcmol} / \mathrm{l}\end{array}$} & before treatment & $345.6 \pm 77.6$ & $338.2 \pm 46.3$ & $322.3 \pm 15.2$ \\
\hline & $\begin{array}{l}\text { after } 3 \text { months } \\
\text { treatment }\end{array}$ & $326.5 \pm 8.4$ & $343.3 \pm 8.4$ & $324.4 \pm 11.6$ \\
\hline & $\begin{array}{l}12 \text { months after the } \\
\text { start of treatment }\end{array}$ & $322.7 \pm 37.9$ & $331.9 \pm 35.9$ & $325.5 \pm 14.6$ \\
\hline
\end{tabular}

Notes: * - significant changes after treatment versus before treatment, $\mathrm{P}<0.05$.

The majority of NAFLD patients with DM-2 (50 of 73; 68.5\%) presented with steatosis in the liver (the 1st stage of NAFLD) without steatohepatitis signs and only in 23 of 73 patients (31.5\%) did we diag- nose mild NASH (the 2nd stage of NAFLD) with a 1.5-2.0 fold increase in ALT. Mild NASH was detected in all 23 NASH patients and zero, moderate or high hepatitis activity degrees were diagnosed. The mean ALT activity in NAFLD with DM-2 patients before treatment was $37.9 \pm 10.5 \mathrm{IU} / 1$. In Group 1 which additionally received EPL and omega-3 PUFA, we observed the mean ALT activity reduction by $15.1 \%$ after 3 months treatment and by $18.1 \%$ after 12 months from the treatment start. In Group 2, where ALA was additionally prescribed, the mean ALT activity decreased by $12.9 \%$ and $15 \%$ respectively. The AST changes demonstrated the same tendency in the abovementioned groups.

The cholestasis intensity was evaluated by GGT and ALP activity. We observed many significant changes after treatment in the Groups 1 and 2 in comparison with Group 3: the mean GGT activity value decreased by $16.7 \%$ in Group 1; by $18.7 \%$ - in Group 2 and only by $9.4 \%$ - in Group 3 respectively after 3 months treatment. 12 months after the start of treatment the mean GGT activity had decreased by $26.4 \%$ in Group 1 , by $28.5 \%$ - in Group 2 respectively in contrast to $13.6 \%$ in Group 3 . The mean ALP activity decreased after treatment in all treatment groups with significant changes both after 3 month treatments and after 12 months. In Group 1 the total protein rate significantly increased after 3 months treatment without significant changes in Groups 2 and 3, showing the improvement in protein-synthetic liver function after additional prescription of EPL and omega-3 PUFA.

We did not find significant pigment metabolism violation in NAFLD patients with DM-2 confirmed by normal total, direct and indirect bilirubin levels in NAFLD patients compared to the control group. Nevertheless, the bilirubin rate was significantly higher in all groups of NAFLD patients with DM-2 versus the control group but remained within reference ranges. The mean creatinine value in NAFLD patients with DM-2 before treatment also was not significantly different in comparison to the control group. This index slightly increased after treatment especially in Group 2 and less in Group 3 but did not exceed the upper limit of normal value.

In NAFLD patients with DM-2 we revealed a tendency to purine metabolism violation but the uric acid level difference was not significant. The level of uric acid was slightly reduced in Group 1 after treatment compared to the initial level without significant difference, probably indicating an indirect impact of hepatoprotector medicines EPL and omega-3 PUFA on the purine metabolism of NAFLD patients.

\section{Discussion}

The results of our clinical trial showed the presence of significant biochemical screen changes in NAFLD and DM-2 patients with carbohydrate metabolism violation confirmed by significantly higher rates of fasting blood glucose $(11.1 \pm 1.78 \mathrm{mmol} / \mathrm{l})$ and $\mathrm{HbA1C}(7.87 \pm 0.52 \%)$ versus the control group $(4.08 \pm 0.59 \mathrm{mmol} / \mathrm{l}$ and $5.13 \pm 0.44 \%$ respecttively, $\mathrm{P}<0.05$ ) associated with insulin resistance of the peripheral tissues demonstrated by significantly higher rate of IR-HOMA $(9.34 \pm 3.42$ in the examined patients versus $2.33 \pm 0.23$ in the control group, $\mathrm{P}<0.05$ ).

Comorbidity is characteristic for NAFLD with frequent other chronic concomitant diseases. According to Patel et al. (2017), the most common comorbidities are MS (94\%), "depression" diagnosed by patients (44\%), coronary heart disease (32\%), obstructive sleep apnea (32\%), and $59 \%$ cases of NAFLD with DM-2 are characterized by polypharmacy (Patel et al., 2017). Jonathan et al. (2016) revealed that NAFLD and DM-2 association leads to a higher rate of treatment resistant DM-2 and diabetic microangiopathy development. At the same time, NAFLD progression rate from steatohepatosis to NASH and liver cirrhosis is much higher in cases of concomitant DM-2.

We revealed dyslipidemia which is characterized by significantly higher rates of total cholesterol, triglicerydes and AIP with significantly lower LDL cholesterol level in NAFLD and DM-2 patients. These results accord with other clinical trials results (Nseir \& Mahamid, 2013) and meet the current recommendations in NAFLD diagnosis and treatment data (EASL-EASD-EASO, 2016).

In NAFLD patients with DM-2, the liver function tests are characterized by the presence of cytolysis and cholestasis laboratory syndromes with preserved protein- and pigment-synthetic functions. The mean 
ALT activity rate before treatment $(37.9 \pm 10.5 \mathrm{IU} / \mathrm{l})$ was 3 fold higher than in the control group $(12.6 \pm 3.1 \mathrm{IU} / 1, \mathrm{P}<0.05)$ and the mean AST activity rate $(33.8 \pm 12.0 \mathrm{IU} / \mathrm{l})$ was respectively 4.06 times higher than in the control group, showing cytolysis and necrotic inflammation changes of liver parenchyma. The mean GGT activity rate in NAFLD patients with DM-2 $(39.3 \pm 12.6 \mathrm{IU} / \mathrm{l})$ was also significantly higher and exceeded the control group GGT rate by 3.84 times $(10.2 \pm 3.6 \mathrm{IU} / \mathrm{l}, \mathrm{P}<$ 0.05 ) and the mean ALP activity rate was 2.03 fold higher in the examined patients versus the control group $(94.8 \pm 14.1 \mathrm{IU} / 1$ and $46.6 \pm 7.1 \mathrm{IU} / 1$ respectively, $\mathrm{P}<0.05$ ) confirming the cholestasis syndrome. We did not find significant changes in total protein, bilirubin and its fractions and creatinine in NAFLD and DM-2 patients in comparison with the control group. That is why, according to our results, we cannot state that the protein-synthetic function and pigments metabolism were violated in the examined NAFLD and DM-2 patients, and kidney function impairment was also not confirmed. The mean uric acid value $(336.2 \pm$ $54.0 \mathrm{mmol} / \mathrm{l})$ was higher than in the control group $(280.2 \pm 22.3 \mathrm{mmol} / \mathrm{l})$ but this difference was not significant $(\mathrm{P}>0.05)$. The revealed tendency to rise in uric acid level demonstrates coexistent purine metabolism impairment in NAFLD and DM-2 patients. Our results are in accordance with similar studies of metabolic changes in NAFLD patients with concomitant DM-2 (Maximos et al., 2015; Buzzetti et al., 2016; Magee et al., 2016; Hansen et al., 2017; Martin-Rodriguez et al., 2017). Lou et al. (2015) revealed that the IR-HOMA rate is significantly higher in NAFLD patients with DM-2 as well as ALT, AST, GGT, total cholesterol, LDL, triglycerides than in NAFLD patients without DM-2 or in DM-2 patients without NAFLD. The same study demonstrated negative correlation of serum omega-3 PUFA with IR-HOMA, triglycerides, LDL and total cholesterol. Most pathogenic hepatocyte damage mechanisms in NAFLD are based on damage to membrane structures (Magee et al., 2016; Hansen et al., 2017). That is why the use of medicines which can regenerate the structure and functions of cell membranes and inhibit the destruction of hepatocytes is advisable. The search of new pharmacotherapy aids is conducted in different directions: looking for hepatoprotector agents that stimulate regeneration processes and the most active detection of hepatoprotectors (Pivtorak, 2017).

Our study demonstrated the good effect of EPL and omega-3 PUFA in addition to the standard treatment for cytolysis and cholestasis inhibition and liver protein-synthetic function improvement. We revealed a tendency to reduction in ALT and AST rates in Group 1 who received EPL and omega-3 PUFA, but those changes were not significant. At the same time, in Group 2 (additional ALA prescription) the ALT and AST rates significantly $(\mathrm{P}<0.05)$ had decreased 12 months after the start of treatment showing long duration and stability of the anticytolitic effect of this treatment combination. Similarly, in Group 3 (rosuvastatin prescription) the ALT and AST activity rates significantly decreased after treatment, which gives a reason to affirm its positive influence on liver function and partly deny hepatotoxic effect. The long-term stable anticholestatic effect was revealed in Groups 1 and 2 confirmed by significant reduction in GGT and ALP rates 2 months the start of treatment. In Group 1, both GGT and ALP rates had significantly decreased after 3 months treatment with preserved effect after 12 months, demonstrating the most prominent and stable hepatoprotector effect of EPL with omega-3 PUFA use among the prescribed combinations and in Group 2 only the ALP level had decreased significantly after 3 months treatment with additional ALA prescription, while GGT demonstrated just a tendency to reduction with significantly lower both ALP and GGT rates after 12 months compared to the initial rates before treatment. In Group 3 (rosuvastatin prescription) only ALP reduction was detected and the GGT rate was not significantly changed.

Our results are consistent with those of other similar investigations of the clinical effect of EPL and omega-3 PUFA (Li et al., 2000; Ohbayashi, 2004; Poongothai et al., 2005; Sas et al., 2013; Lou et al., 2014; Gundermann et al., 2016; Stepanov, 2016; Martinez-Rodriguez et al., 2017). The Kokran review (Lombardi et al., 2017), which includes 77 clinical trials with 6,287 NFLD patients examined, showed ambiguous data regarding efficacy of different pharmacological treatments including EPL, omega-3 PUFA and ALA use. The beneficial pathogenic effects of EPL are well-known. The complex EPL-based medicines contain multiple phospholipids in combination with vitamins and lead to appropriate biochemical reactions that meet urgent hepatocytes demands (Pivtorak, 2017). Many scientists state a positive effect of EPL represented by resolution of clinical symptoms and improvement in laboratory test results (decreasing of ALT, AST activity rates), ultrasound signs of liver fibrosis reduction (Wu, 2009; Padma, 2013). Gundermann (2016) published a review of 45 clinical trials where EPL were used in NAFLD patients, 2 of them were double-blind. The daily dose of EPL varied from 1.05 to $1.8 \mathrm{~g}$ and treatment course duration was from 4 weeks to 2 years. In the majority of these trials EPL were prescribed in the daily dose of $1.8 \mathrm{~g}$ for 3-6 months. In several studies the therapy started from $500-1000 \mathrm{mg}$ of EPL for 10 days -4 weeks with further oral prescription. In one trial $500 \mathrm{mg}$ of EPL were prescribed for 30 days. In an open randomized trial by Dajani et al. (2015) with 324 patients (113 were NAFLD patients, 107 - NAFLD with DM-2 and 104 - NAFLD with combined dyslipidemia patients respectively) the diet and physical exertion were combined with $1,800 \mathrm{mg}$ of EPL daily for 24 weeks with the dose reduction to $900 \mathrm{mg}$ per day for the following 48 weeks. The results demonstrated good general and gastrointestinal symptoms improvement in NAFLD patients with significant reduction in ALT and AST activity rates, which were high before treatment. The ultrasound showed normalization in $4.6 \%$ and shift from the $2^{\text {nd }}$ to $1^{\text {st }}$ NAFLD stage in $24 \%$ of patients.

Despite there being reasonable mechanisms of potential EPL influence on the main NAFLD pathogenic links, the results of some clinical trials have not confirmed their efficacy (Sanyal et al., 2014).

We obtained interesting results of the impact of treatment on lipid metabolism. In Group 3 which received rosuvastatin, the total cholesterol rate decreased by the highest degree as was expected but the lowest mean triglycerides level 12 months after the start of treatment was revealed in Group 1, not Group 3. In the same Group 1 there was a maximal (among the 3 treatment groups) HLD level rise demonstrating good effect of EPL and omega-3 PUFA on lipid metabolism improvement. In Group 1, the total cholesterol level reduction was comparable to that of Group 3; at the same time in Group 1, we observed reduction in the triglycerides level with increase in the HLD level, which demonstrates an anti-atherogenic effect. The hypotriglyceridemic effect of EPL and omega-3 PUFA combination in Group 1 is particularly important since triglycerides cause liver steatosis accumulating in heaptocytes in cases of NAFLD.

According to EASL-EASD-EASO (2016) recommendations, omega-3 PUFA can be considered as the first line treatment of triglyceridemia in NAFLD patients but cannot be recommended for the specific NAFLD therapy yet (class 1 recommendations, evidency level B). The first trial of siliphos-selenium-methionine-alpha lipoic acid effect in NAFLD patients (Martinez-Rodriguez et al., 2014) showed that combined use of selenium $15 \mathrm{mg}$, methionine $3 \mathrm{mg}$ and ALA $200 \mathrm{mg}$ for 24 weeks additionally to metformin $1500 \mathrm{mg}$ led to the steatosis reduction by $70 \%$ according to ultrasound results versus $15 \%$ in patients who received only metformin $1500 \mathrm{mg}$ daily. This combined therapy promoted better antioxidant protection, liver transaminases activity reduction, steatosis progression prevention and anti-inflammatory profile improvement in NAFLD patients.

Kajikawa et al. (2011) in a prospective double-blind placebo controlled trial in 37 North American clinical centers investigated the efficacy of ethyl-eicosapentaenic acid in different dosing, which is an omega-3 PUFA well known for its insulin resistance, lipogenesis and inflammation reduction leading to NAFLD activity inhibition. This trial demonstrated the good effect of omega-3 PUFA for NAFLD clinical course improvement, hepatocytes triglycerides level correction and ALT activity reduction. The liver oxidative stress indicators (free fatty acids, TNF-factor, serum ferritin and thioredoxin) rates were significantly reduced but the body mass, blood glucose, insulin and adiponectin levels were not changed significantly.

Di Minno et al. (2012) described 7 clinical trials of omega-3 PUFA efficacy in NAFLD patients; the largest study involved 177 NAFLD patients who received omega-3 PUFA for 6 months and showed its advisability in complex NAFLD treatment. In contrast to the abovementioned study, Sanyal et al. (2014) demonstrate an absence of significant 
liver histology changes after omega-3 PUFA therapy. In a randomized, placebo-controlled open prospective clinical trial Basu et al. (2014) investigated efficacy of antioxidants in overweight and obesity patients (body mass index (BMI) $28-33 \mathrm{~kg} / \mathrm{m}^{2}$ ) with ultrasound liver steatosis signs. The patients walked $150 \mathrm{~min}$ per week (at least 100 steps per minute) and consumed less than 1600 calories daily. Comparison of 3 treatment groups (additional $30 \mathrm{mg}$ of ALA prescription -40 patients, Vitamin E 700 Units - 40 patients and ALA 300mg + Vitamin E 400 Units -40 patients) to the placebo group ( 35 patients) after 6 months showed significant improvement of cytokine profile, steatosis, IR-HOMA, triglycerides level in all 3 treatment groups. This study demonstrated that ALA monotherapy led to reduction of IR-HOMA by $54.3 \%$, triglycerides rate - by $34.4 \%$, leptin level - by $44.8 \%$, Hb1AC - by $13.6 \%$, ALT activity - by $20.8 \%$, fibrosis degree - by $5.9 \%$ and adiponectin concentration increased from 0.9 to $2.0 \mathrm{mcg} / \mathrm{ml}$ (by $122.2 \%$ ).

Another randomized, double-blind, placebo-controlled trial (de Oliveira et al., 2011) showed similar results. The same medicines were used but the dosing and treatment duration were different: ALA $600 \mathrm{mg}$ or alpha-tocopherol $800 \mathrm{mg}$ or ALA $600 \mathrm{mg}+$ alpha tocopherol $800 \mathrm{mg}$ for 4 months but the significant lipid and biochemical profile changes were revealed only after combined ALA + Vitamin E therapy in contrast to the ALA monotherapy which led to non-significant changes probably related to insufficient treatment duration. The only significant difference after treatment vs before treatment obtained in all treatment groups was improvement in the pro / antioxidant system indices showing the good antioxidant effect of the prescribed agents.

Several clinical trials revealed the good lipid reduction effect of statins in NAFLD patients: Argo et al. (2008) showed the efficacy of atorvastatin and Riche et al. (2014) - of statins and pioglitazone respecttively. At the same time, there are different even controversial opinions regarding the use of statins in NAFLD patients. In particular, statins are not recommended in NASH patients due to possible toxic effects (Nseir \& Mahamid, 2013). At the same time, Neto-Ferreira's (2013) study showed glucose tolerance improvement and insulin resistance reduction in mice after rosuvastatin use and Riche et al. (2014) showed improvement in biochemical and ultrasound NAFLD markers. We have not found toxic effects of rosuvastatin in any our patients, even the oppositemean ALT, AST and GGT activity in patients who received rosuvastatin (Group 3) decreased after treatment versus before treatment. This result allows us to state an absence of hepatotoxic rosuvastatin effect in cases of prescription in daily dose of $10 \mathrm{mg}$. The hypolipidemic effect of EPL and omega-3 PUFA combination or ALA in Groups 1 and 2 shows the advisability of using these agents in treating NAFLD patients with DM-2 as an alternative dyslipidemia correction method in cases of low efficacy of rosuvastatin $10 \mathrm{mg}$ daily and the necessity to increase the dose of rosuvastatin. The remote consequences after combined treatment used in our study can be explained by modified life style habit development in our patients during the 3 month treatment course that persists after the end of the 3 month pharmacotherapy course.

\section{Conclusions}

Along with life style modification and diet correction in patients with non-alcoholic fatty liver disease with type 2 diabetes mellitus, pharmacotherapy with essential phospholipids with omega- 3 polyunsaturated fatty acids or alpha lipoic acid additionally to metformin is advisable. The abovementioned treatment combinations led to biochemical screen correction in such patients due to both cytolysis and cholestasis as well as improvement in dyslipidemia laboratory indices with reduction in hepatocytes triglycerides deposits. The combined treatment with additional prescription of essential phospholipids with omega-3 polyunsaturated fatty acids or alpha lipoic acid might become a good alternative to rosuvastatin due to their good hypolipidemic, hypotriglyceridemic and hepatoprotector effects.

Since the laboratory parameters we investigated characterize rather the conditions in which non-alcoholic fatty liver disease (carbohydrate and lipid metabolism impairment, type 2 diabetes mellitus with overweight or obesity) occurs than non-alcoholic fatty liver disease itself and manifestations of cytolysis and cholestasic laboratory syndromes are non-specific, our results can be interpreted only as the "tip of the iceberg" of non-alcoholic fatty liver disease. That's why investigation of essential phospholipids with omega-3 polyunsaturated fatty acids or alpha lipoic acid influence on the interleukin system, leptin, adyponectin and other indices that characterize molecular aspects and genetic features of non-alcoholic fatty liver disease is promising in order to determine a personalised approach for each patient and directly impact on the treatment effect. Such study will give an opportunity to avoid a "superficial" approach and give a pathogenic clarification of some of the laboratory changes revealed in this study.

\section{References}

Anavi, S., Madar, Z., \& Tirosh, O. (2017). Non-alcoholic fatty liver disease, to struggle with the strangle: Oxygen availability in fatty livers. Redox Biology, $13,386-392$.

Argo, C. K., Loria, P., Caldwell, S. H., \& Lonardo, A. (2008). Statins in liver disease: A molehill, an iceberg, or neither? Hepatology, 48(2), 662-669.

Armstrong, M. J., Hazlehurst, J. M., Hull, D., Guo, K., Borrows, S., Yu, J. Gough, S. C., Newsome, P. N., \& Tomlinson, J. W. (2014). Abdominal subcutaneous adipose tissue insulin resistance and lipolysis in patients with non-alcoholic steatohepatitis. Diabetes, Obesity and Metabolism, 16, 651-660.

Babio, N., Toledo, E., Estruch, R., Ros, E., Martínez-González, M. A., \& Castañer, O. (2014). Mediterranean diets and metabolic syndrome status in the Predimed randomized trial. Canadian Medical Association Journal, 186(17), 649-657.

Ballestri, S. (2016). Nonalcoholic fatty liver disease is associated with an almost two-fold increased risk of incident type 2 diabetes and metabolic syndrome. Evidence from a systematic review and meta-analysis. Journal of Gastroenterology and Hepatology, 31(5), 936-944.

Basu, P. P., Shah, N. J., Aloysius, M. M., \& Brown Jr., R. S. (2014). Effect of vitamin $\mathrm{E}$ and alpha lipoic acid in nonalcoholic fatty liver disease: A randomized, placebo-controlled, open-label, prospective clinical trial (vain trial). Open Journal of Gastroenterology, 4, 199-207.

Bedogni, G., Kahn, H. S., Bellentani, S., \& Tiribelli, C. (2010). A simple index of lipid overaccumulation is a good marker of liver steatosis. BMC Gastroenterology, 10, 98 .

Berlanga, A., Guiu-Jurado, E., Porras, J. A., \& Auguet, T. (2014). Molecular pathways in non-alcoholic fatty liver disease. Clinical and Experimental Gastroenterology, 7, 221-239.

Berzigotti, A., Ferraioli, G., Bota, S., Gilja, O. H., \& Dietrich, C. F. (2018). Novel ultrasound-based methods to assess liver disease: The game has just begun. Digestive and Liver Disease, 50(2), 107-112.

Brunt, E. M., \& Tiniakos, D. G. (2010). Histopathology of nonalcoholic fatty liver disease. World Journal of Hepatology, 16(42), 5286-5296.

Buzzetti, E., Pinzani, M., \& Tsochatzis, E. A. (2016). The multiple-hit pathogenesis of non-alcoholic fatty liver disease (NAFLD). Metabolism, 65(8), 1038-1048.

Dai, H., Wang, W., Chen, R., Chen, Z., Lu, Y., \& Yuan, H. (2017). Lipid accumulation product is a powerful tool to predict non-alcoholic fatty liver disease in Chinese adults. Nutrition and Metabolism, 1, 1449.

Dajani, A., \& Abu Hammour, A. (2016). Treatment of nonalcoholic fatty liver disease: Where do we stand? An overview. Saudi Journal of Gastroenterology, 22(2), 91-105.

Dajani, A. I., Abu Hammour, A. M., Zakaria, M. A., Al Jaberi, M. R., Nounou, M. A., \& Semrin, A. I. (2015). Essential phospholipids as a supportive adjunct in the management of patients with NAFLD. Arab Journal of Gastroenterology, 16(3-4), 99-104.

de Oliveira, A. M., Rondo, P. H., Luzia, L. A., D’Abronzo, F. H., \& Illison, V. K. (2011). The effects of lipoic acid and alpha-tocopherol supplementation on the lipid profile and insulin sensitivity of patients with type 2 diabetes mellitus: A randomized, double-blind, placebo-controlled trial. Diabetes Research and Clinical Practice, 92, 253-260.

Di Minno, M. N., Russolillo, A., Lupoli, R., Ambrosino, P., Di Minno, A., \& Tarantino, G. (2012). Omega-3 fatty acids for the treatment of non-alcoholic fatty liver disease. World Journal of Gastroenterology, 18, 5839-5847.

EASL-EASD-EASO (2016). Clinical practice guidelines for the management of non-alcoholic fatty liver disease. Journal of Hepatology, 64(6), 1388-1402.

Federico, A., Dallio, M., Caprio, G. G., Gravina, A. G., Picascia, D., Masarone, M., Persico, M., \& Loguercio, C. (2017). Qualitative and quantitative evaluation of dietary intake in patients with non-alcoholic steatohepatitis. Nutrients, 9(10), e1074.

Firneisz, G. (2014). Non-alcoholic fatty liver disease and type 2 diabetes mellitus: The liver disease of our age? World Journal of Gastroenterology, 20(27), 9072-9089.

Gaggini, M., Morelli, M., Buzzigoli, E., DeFronzo, R. A., Bugianesi, E., \& Gastaldelli, A. (2013). Non-alcoholic fatty liver disease (NAFLD) and its con- 
nection with insulin resistance, dyslipidemia, atherosclerosis and coronary heart disease. Nutrients, 5, 1544-1560.

Ganesh, S., \& Rustgi, V. K. (2016). Current pharmacologic therapy for nonalcoholic fatty liver disease. Clinics in Liver Disease, 20(2), 351-364.

Gastaldelli, A., Cusi, K., Pettiti, M., Hardies, J., Miyazaki, Y., Berria, R., Buzzigoli, E., Sironi, A. M., Cersosimo, E., \& Ferrannini, E. (2007). Relationship between hepatic/visceral fat and hepatic insulin resistance in nondiabetic and type 2 diabetic subjects. Gastroenterology, 133, 496-506.

Gonciarz, Z., Besser, P., Lelek, E., Gundermann, K. J., \& Johannes, K. J. (1988) Randomised placebo-controlled double blind trial on "essential" phospholipids in the treatment of fatty liver associated with diabetes. Medecine et Chirurgie Digestives, 17(1), 61-65.

Gundermann, K.-J., Gundermann, S., Drozdzik, M., \& Mohan Prasad, V. G. (2016). Essential phospholipids in fatty liver: A scientific update. Clinical and Experimental Gastroenterology, 9, 105-117.

Hansen, H. H., Feigh, M., Veidal, S. S., Rigbolt, K. T., Vrang, N., \& Fosgerau, K. (2017). Mouse models of nonalcoholic steatohepatitis in preclinical drug development. Drug Discovery Today, 22(11), 1707-1718.

Hazlehurst, J. M., Woods, C., Marjot, T., Cobbold, J. F., \& Tomlinson, J. W. (2016). Non-alcoholic fatty liver disease and diabetes. Metabolism, 65(8), 1096-1108.

Kajikawa, S., Imada, K., Takeuchi, T., Shimizu, Y., Kawashima, A., \& Harada, T. (2011). Eicosapentaenoic acid attenuates progression of hepatic fibrosis with inhibition of reactive oxygen species production in rats fed methionine- and choline-deficient diet. Digestive Diseases and Sciences, 56, 1065-1074.

Kim, W. (2017). [Treatment options in non-alcoholic fatty liver disease]. Korean Journal of Gastroenterology, 69(6), 353-358 (in Korean).

Lazo, M., Hernaez, R., Eberhardt, M. S., Bonekamp, S., Kamel, I., Guallar, E., Koteish, A., Brancati, F. L., \& Clark, J. M. (2013). Prevalence of nonalcoholic fatty liver disease in the United States: The Third National Health and Nutrition Examination Survey, 1988-1994. American Journal of Epidemiology, 178, 38-45

Lee, D. H. (2017). Imaging evaluation of non-alcoholic fatty liver disease: Focused on quantification. Clinical and Molecular Hepatology, 23, 290-301.

Lee, H. W., Kim, B. K., Kim, S. U., Park, J. Y., Kim, D. Y., Ahn, S. H., Kim, K. J., \& Han, K. H. (2017). Prevalence and predictors of significant fibrosis among subjects with transient elastography-defined nonalcoholic fatty liver disease. Digestive Diseases and Sciences, 62(8), 2150-2158.

Li, J. H., Chen, X. Y., Zhong, C. F., \& Min, J. (2000). A randomized controlled study of essential phospholipids (Essentiale capsules) in the treatment of fatty liver. Infectious Diseases Info, 13(4), 180-181.

Lombardi, R., Onali, S., Thorburn, D., Davidson, B. R., Gurusamy, K. S., \& Tsochatzis, E. (2017). Pharmacological interventions for non-alcohol related fatty liver disease (NAFLD): An attempted network meta-analysis. Cochrane Database of Systematic Reviews, 3, CD011640pub2.

Loomba, R., \& Sanyal, A. J. (2013). The global NAFLD epidemic. Nature Reviews Gastroenterology and Hepatology, 10, 686-690.

Lou, D. J., Zhu, Q. Q., Si, X. W., Guan, L. L., You, Q. Y., Yu, Z. M., \& Zhang, A. Z. (2014). Serum phospholipid omega-3 polyunsaturated fatty acids and insulin resistance in type 2 diabetes mellitus and non-alcoholic fatty liver disease. Journal of Diabetes Complications, 28(5), 711-714.

Machado, M. V., \& Cortez-Pinto, H. (2014). Non-alcoholic fatty liver disease: What the clinician needs to know. World Journal of Gastroenterology, 20(36), 12956-12980.

Magee, N., Zou, A., \& Zhang, Y. (2016). Pathogenesis of nonalcoholic steatohepatitis: Interactions between liver parenchymal and nonparenchymal cells. BioMed Research International, 2016, 1-11.

Martínez-Rodríguez, L. A., Rojas, S. J., \& Aldo, T. (2014). Siliphos selenium methionine alpha lipoic acid for non alcoholic fatty liver disease: Results of a pilot study. Journal of Clinical and Experimental Pharmacology, 4, 167.

Martin-Rodriguez, J. L., Gonzalez-Cantero, J., Gonzalez-Cantero, A., Arrebola, J. P., \& Gonzalez-Calvin, J. L. (2017). Diagnostic accuracy of serum alanine aminotransferase as biomarker for nonalcoholic fatty liver disease and insulin resistance in healthy subjects, using 3T MR spectroscopy. Medicine (Baltimore), 96(17), e6770.

Maximos, M., Bril, F., Portillo Sanchez, P., Lomonaco, R., Orsak, B., Biernacki, D., Suman, A., Weber, M., \& Cusi, K. (2015). The role of liver fat and insulin resistance as determinants of plasma aminotransferase elevation in nonalcoholic fatty liver disease. Hepatology, 61(1), 153-160.

Michelotti, G. A., Machado, M. V., \& Diehl, A. M. (2013). NAFLD, NASH and liver cancer. Nature Reviews of Gastroenterology and Hepatology, 10(11), 656-665.

Musso, G., Gambino, R., Cassader, M., \& Pagano, G. (2011). Meta-analysis: Natural history of non-alcoholic fatty liver disease (NAFLD) and diagnostic accuracy of non-invasive tests for liver disease severity. Annals of Medicine, $43,617-649$.
Newsome, P. N., Cramb, R., Davison, S. M., Dillon, J. F., Foulerton, M., Godfrey, E. M., Hall, R., Harrower, U., Hudson, M., Langford, A., Mackie, A., Mitchell-Thain, R., Sennett, K., Sheron, N. C., Verne, J., Walmsley, M., \& Yeoman, A. (2018). Guidelines on the management of abnormal liver blood tests. Gut, 67, 6-19.

Nseir, W., \& Mahamid, M. (2013). Statins in nonalcoholic fatty liver disease and steatohepatitis: Updated review. Current Atherosclerosis Reports, 15, 305.

Ohbayashi, H. (2004). Twelve-month chronic administration of polyenephosphatidylcholine $(E P L \circledR)$ for improving hepatic function of fatty liver patients. Progress of Medicine, 24(7), 1751-1756.

Padma, L., Mukaddam, Q., \& Trailokya, A. (2013). An observational study of Essentiale-L in the treatment of patients with fatty liver disease. Indian Journal of Clinical Practice, 23, 735-739.

Patel, P. J., Hayward, K. L., Rudra, R., Horsfall, L. U., Hossain, F., Williams, S., Johnson, T., Brown, N. N., Saad, N., Clouston, A. D., Stuart, K. A., Valery, P. C., Irvine, K. M., Russell, A. W., \& Powell, E. E. (2017). Multimorbidity and polypharmacy in diabetic patients with NAFLD: Implications for disease severity and management. Medicine (Baltimore), 96(26), e6761.

Perazzo, H., \& Dufour, J. F. (2017). The therapeutic landscape of non-alcoholic steatohepatitis. Liver International, 37(5), 634-647.

Pivtorak, K. V. (2017). Features of nonalcoholic fatty liver disease pharmacotherapy in patients with overweight and obesity. Zaporozhye Medical Journal, 19(4), 520-524.

Poongothai, S., Karkuzhali, K., \& Siva Prakash, G. (2005). Effect of essentiale in diabetic subjects with non-alcoholic fatty liver. International Journal of Diabetes in Developing Countries, 25(1), 12-19.

Riche, D. M., Fleming, J. W., Malinowski, S. S., Black, C. A., Miller, K. H., \& Wofford, M. R. (2014). Resistant nonalcoholic fatty liver disease amelioration with rosuvastatin and pioglitazone combination therapy in a patient with metabolic syndrome. Annals of Pharmacotherapy, 48, 137-141.

Sanyal, A. J., Abdelmalek, M. F., Suzuki, A., Cummings, O. W., \& Chojkier, M. (2014). EPE-A Study Group. No significant effects of ethyl-eicosapentanoic acid on histologic features of nonalcoholic steatohepatitis in a phase 2 trial. Gastroenterology, 147, 377-384.

Sas, E., Grinevich, V., Efimov, O., \& Shcherbina, N. (2013). Beneficial influence of polyunsaturated phosphatidylcholine enhances functional liver condition and liver structure in patients with nonalcoholic steatohepatitis accompanied by diabetes type 2 . Results of prolonged randomized blinded prospective clinical study [abstract]. Journal of Hepatology, 58, S549.

Schleicher, J., Guthke, R., Dahmen, U., Dirsch, O., Holzhuetter, H. G., Schuster, S. (2014). A theoretical study of lipid accumulation in the liver-implications for nonalcoholic fatty liver disease. Biochimica et Biophysica Acta, 1841(1), 62-69.

Sharma, M., Mitnala, S., Vishnubhotla, R. K., Mukherjee, R., Reddy, D. N., \& Rao, P. N. (2015). The riddle of nonalcoholic fatty liver disease: Progression from nonalcoholic fatty liver to nonalcoholic steatohepatitis. Journal of Clinical and Experimental Hepatology, 5(2), 147-158.

Stankovic, M. N., Mladenovic, D., Ninkovic, M., Đuricic, I., Sobajic, S., Jorgacevic, B., de Luka, S., Vukicevic, R. J., \& Radosavljevic, T. S. (2014). The effects of a-lipoic acid on liver oxidative stress and free fatty acid composition in methionine-choline deficient diet-induced NAFLD. Joumal of Medicinal Food, 17(2), $254-261$.

Stepanov, Y., Nedzvetskaya, N., Yagmur, V., \& Kononenko, I. (2018). The significance of hepatic transaminases and ultrasound in the diagnosis of non-alcoholic fatty liver disease. Regulatory Mechanisms in Biosystems, 9(1), 105-111.

Stepanov, Y. M. (2016). The ese of essential phospholipids for the treatment of fatty liver disease. Gastroenterology, 62, 58-64.

Sumida, Y., Nakajima, A., \& Itoh, Y. (2014). Limitations of liver biopsy and noninvasive diagnostic tests for the diagnosis of nonalcoholic fatty liver disease / nonalcoholic steatohepatitis. World Journal of Gastroenterology, 20(2), 475-485.

Takahashi, Y., \& Fukusato, T. (2014). Histopathology of nonalcoholic fatty liver disease/nonalcoholic steatohepatitis. World Journal of Gastroenterology, 20(42), 15539-15548.

Verbeek, J., Cassiman, D., Lannoo, M., Laleman, W., van der Merwe, S., Verslype, C., Van Steenbergen, W., \& Nevens, F. (2013). Treatment of nonalcoholic fatty liver disease: Can we already face the epidemic? Acta GastroEnterologica Belgica, 76(2), 200-209.

Williams, C. D., Stengel, J., Asike, M. I., Torres, D. M., Shaw, J., Contreras, M., Landt, C. L., \& Harrison, S. A. (2011). Prevalence of nonalcoholic fatty liver disease and nonalcoholic steatohepatitis among a largely middle-aged population utilizing ultrasound and liver biopsy: a prospective study. Gastroenterology, 140, 124-131.

Wu, Y. (2009). Effective analysis of type 2 diabetic united adiposis hepatica with polyene phosphatidylcholine. Journal of Traditional Chinese Medicine, 29, 41-42. 